\title{
For the New, the Former, and All Those Continuing On: We Offer Our Thanks
}

\author{
Leigh E. Rich
}

Received: 31 January 2016/Accepted: 21 February 2016/Published online: 3 March 2016

(C) Journal of Bioethical Inquiry Pty Ltd. 2016

"Silent gratitude isn't very much to anyone."

- Gertrude Stein

"Gratitude is not only the greatest of virtues, but the parent of all the others." - Cicero

For those within academic publishing, it is no secret that countless individuals often share their time and expertise gratis, though many outside of this realm might be unaware of (or unengaged by) this fact. It is a tradition that has its roots in the history of journal publishing (with Philosophical Transactions editor Henry Oldenburg often on the hook for paper, ink, and postage [see Tucker 2011]) as well as a duty and desire among scholars to engage as a community and safeguard the production of knowledge. Although modern academic journal publishing has in many ways become rather lucrative, the practice is sustained by those who, often without clear remuneration, facilitate and oversee review processes, engage in the essential labour of evaluating, appraising, and improving work, and put the finishing touches on the product so that it employs intelligible language, appropriate methods, and proper citation and referencing styles. These tasks frequently are completed in between teaching classes, seeing patients, balancing time with family, and attending to the self. And - perhaps like a perverse form of capital, which has the capacity to reproduce itself- those who carry out

\section{E. Rich $(\bowtie)$}

Department of Health Sciences (Public Health), Armstrong State University, 11935 Abercorn Street, University Hall 154F,

Savannah, GA 31419, USA

e-mail: leigh.rich@armstrong.edu such duties more efficiently and effectively typically are asked to take on more.

And with the enduring momentum of the great publishing wheel, which excitedly travels from one issue to the next, there is little time to stop along the journey and pause to express thanks. Manuscript submissions increase, time for peer review plummets, revisions are due, proofs need to be checked, the next deadline looms. It is thus easy to be silent and simply move on to the next chore, but as Gertrude Stein once said, that "isn't very much to anyone" (Mahoney 2008, 135).

So, for the fourth year in a row, we publish here a brief note of gratitude to all who make the Journal of Bioethical Inquiry (JBI) possible — even though such words aren't much and cannot compare to the efforts they have expended. This is especially so in regards to our peer reviewers, whose work, like with many journals, happens behind the scenes with little recognition. We reserve this column each year in order to highlight their names. Please find this list of dedicated $J B I$ reviewers for 2015 below.

We also extend kudos to Ian Kerridge, a member of the $J B I$ executive committee, who was honoured by Australia's National Health and Medical Research Council last year with its ethics award (NHMRC 2015), as well as Floor Oosting, our publishing editor at Springer, who has been promoted to senior publishing editor for applied ethics. Ian tirelessly (and never without good humour) helps guide the $J B I$, accepts assignments orphaned by all, and turns around projects in record time. In keeping multiple plates spinning without fail, he is often neither seen nor heard, but the effects of his 
presence positively linger. We also know that all of the journals now under Floor's direction will flourish, like she has made possible for the $J B I$, thanks to her talents, skills, professionalism, patience, and authenticity. We are lucky to continue to have both Ian and Floor in our midst.

While the $J B I$ has grown in terms of pages over the past year (bursting at the seams as never before!), our core team hasn't expanded as much. However, we very much welcomed Gordon Campbell of Australia to our copy-editing team as well as Ilaria Walker, who steps into Floor's shoes as the JBI publishing editor at Springer. We also would like to extend our thanks to Carmina Cayago, who, among other duties, assists both $J B I$ authors and editors with technical and other questions related to the online manuscript submission system; Chris Wilby at Springer, now a senior publishing assistant, who has tended to the $J B I$ with care for several years; and Catherine Murphy, the JBI's production editor at Springer, and her team, who transform all of the pieces into a cohesive final product with great diligence, flexibility, advocacy, and patience. And a few members have moved on. Martha Stoddard-Holmes of California State University completed a long tour with the $J B I$ as associate editor of "Literature and Medicine"; Ainsley Newson of the University of Sydney was one of the two associate editors leading the journal's "Science and Genetics" portfolio; and Sheila Pham of Australia provided much-needed technological and Web-based assistance. Though their absence and collegiality are already felt within the $J B I$ community, we heartily wish them the best in all of their endeavours.

For the new, the former, and all those continuing on, the $J B I$ (and I) cannot express sufficient gratitude. We appreciate the work, the wisdom, and the wherewithal you bring to the $J B I$ team - all of our associate editors, copy editors, founding and executive members, ombudsman, international team of legal scholars, advisory board members, and colleagues at Springer.

And always mentioned last - but clearly without whom the $J B I$ as either an academic journal or, more importantly, an interdisciplinary community of scholars and professionals dedicated to ethics in health wouldn't exist-are our editorial board chair Paul Komesaroff, who keeps this vehicle always travelling towards our destination while exploring new paths; consulting editors Michael Ashby and David Shaw, skilled, insightful, and forward-looking navigators, whose guidance and collaborations on this journey improve the literature and knowledge base; Grant Gillett, Ian Kerridge, Neil Pickering, and Colin Thomson, who keep the machine oiled and running; and managing editor Bronwen Morrell, whose infinite talents ensure the expert performance of ceaseless jobs every kilometer of the way, running the gamut from start to finish, from seemingly small (but crucial) tasks to those looming and large-essentially without whom there would be no vehicle at all. Their many abilities, virtuous characters, unflagging efforts, careful thinking, inspired writing, considerate mentoring, excellent wit, and infectious personalities enable the $J B I$ - and all connected to it - to reach for brass rings.

"No one who achieves success," so mused Alfred North Whitehead, "does so without the help of others. The wise and confident acknowledge this help with gratitude."

If I possess any wisdom or confidence, it is the direct result of my ever fortunate interactions with each and every member of the $J B I$ team-including those not mentioned specifically here by name. (Please see the masthead in this and previous issues as well as http:// bioethicalinquiry.com/editorial-team/ to see how lucky we really are!) I cannot repay their trust, guidance, friendship, and kindness and thus remain, now and always, clearly in their debt.

This is but a paltry acknowledgement to those whose work positively impacts bioethics knowledge, practice, and the lives of many in both great ways and small.

Thank you to all.

Below, please find a special round of thanks to all who have served as a peer reviewer for one or more articles over the past year, from January 2015 to January 2016.

Alejandra Mancilla

Ali Khan

Amrita Banerjee

Amy Vidali

An Ravelingien

Andreas Vilhelmsson

Andrew Cooper

Andrew Knight

Angela Ballantyne

Angela Kelly-Hanku

Anna Smajdor

Anne Scott

Anne-Maree Farrell

Annemarie Jutel

Arianne Shahvisi

Aric Bendorf

Assim Padela 
Barbara Mintzes

Barry Jubraj

Ben A. Rich

Bernadette Tobin

Betty Levin

Bharat Jayram Venkat

Brandon Brown

Brandon Kohrt

Bridget Haire

Britt E. Johnson

Calvin Ho

Carolyn Hayes

Carwyn Hooper

Charles Douglas

Christopher James Ryan

Christopher Robertson

Claire Hooker

Clare Delaney

Clayton Clark

Colleen Cartwright

D. Gilson

Damian Adams

Daniel Fu-Chang Tsai

Daniel Morrison

Daniela Cutas

David Buchanan

David Courtwright

David Isaacs

Dennis Cooley

Diana Tietjens Meyers

Diedre Anglin

Dirksen Bauman

Donald Chi

Donald Thompson

Donna Dickenson

Douglas Hutchinson

Edward Wheatley

Else Vogel

Emilio Dirlikov

Emily Postan

Enrique Gavilán-Moral

Erin Heidt-Forsythe

Esther Speight

Gabriel Sayegh

Graham Mooney

Heath Fogg Davis

Helen Bynum

Helen J. Davidson

Helen MacDonald
Henry Kilham

Hsien-Cheng Lin

Hub Zwart

Hudson Henry Birden

I. Glenn Cohen

Iain Brassington

Ian Scott

Iris Bergmann

Isabel Karpin

Israel Berger

Jack A. Kilcullen

Jacob Busch

Jaime Cantrell

Jami Anderson

Jan Angus

Jay Sibara

Jeanne Snelling

Jeannette Pols

Jens Seeberg

Jeremy Mennis

Jeremy Wickins

Joe Brierley

Joel Lexchin

Joel Marks

Johan Christiaan Bester

John McMillan

Jonathan Moreno

Joseph F. Kras

Joseph Shaw

Judy Segal

Justin Sanchez

Kara Elizabeth Thompson

Kasper Raus

Katayoun Chamany

Katherine Prendergast

Kathrin Herrmann

Katrina Jaworski

Kenneth Robert Abbey

Kim Q. Hall

Kirsty Horsey

L. Syd M. Johnson

Laura Buccini

Laura Mauldin

Letitia Helen Burridge

Lynn Woodward

Malcolm Keith Smith

Marcus Agnafors

Marie Bismark

Martha Jones 
Mary Ann McCabe

Matthew Steven Lucas

Maya Sabatello

Melissa McCullough

Michael David Dahnke

Michael Loughlin

Michael Mason

Michael Montoya

Michelle A. Groman

Michelle de Souza

Miles Little

Moriah McSharry McGrath

Nancy S. Jecker

Neil Price

Nicholas J. Lennings

Nicholos Kontos

Nicolae Morar

Noam Ostrander

Paolo Palladino

Paul B. Thompson

Paul Howard Mason

Paul Lombardo

Paula A. Treichler

Paula Saravia

Pauline Lane

Pawan Singh

Peter Fraenkel

Peter Saul

Rachel Ankeny

Raymond Devettere

Reem Sweid

Renaud F. Boulanger

Richard Cooper

Rosalind McDougall

Sabine Salloch
Sandra Bradley

Sascha Callaghan

Scott Santibanez

Shahram Ahmadi Nasab Emran

Sheryl de Lacey

Simon Richard Walters

Simon Woods

Srila Roy

Stephen G. Henry

Susan MacCallum

Susannah Mintz

Tamra Lysaght

Tenzin Wangmo

Thomas Couser

Thomas David Harter

Tim Carey

Timothy Murphy

Tina Cockburn

Tommaso Bruni

Trish Dunning

Wannes Van Hoof

Warren Bell

William Bülow

Zabidi Hussin

\section{References}

Mahoney, J.M. 2008. Topsy turvy: A book of quotations. Bloomington, IN: AuthorHouse.

National Health and Medical Research Council (NHMRC). 2015. Highest-ranked stars of medical research recognized. https:// www.nhmrc.gov.au/media/releases/2015/highest-rankedstars-medical-research-recognised. Accessed February 10, 2016.

Tucker, H. 2011. Blood work: A tale of medicine and murder in the Scientific Revolution. New York: W. W. Norton \& Company. 